14.1

\title{
Взаимосвязь спектров поглощения пигментов растений и светодиодного освещения с различным спектральным составом
}

\author{
() Т.Э. Кулешова, ${ }^{1}$ А.И. Лихачев, ${ }^{1}$ Е.С. Павлова, ${ }^{1}$ Д.О. Кулешов, ${ }^{2}$ А.В. Нащекин, ${ }^{1}$ Н.Р. Галль ${ }^{1,2}$ \\ ${ }^{1}$ Физико-технический институт им. А.Ф. Иоффре РАН, \\ 194021 Санкт-Петербург, Россия \\ ${ }^{2}$ Институт аналитического приборостроения РАН, \\ 198095 Санкт-Петербург, Россия \\ e-mail: www.piter.ru@bk.ru
}

(Поступило в Редакцию 28 ноября 2017 г.)

\begin{abstract}
Представлены спектры поглощения пигментов, выделенных из растений, освещаемых в процессе роста светом с различным спектральным составом. Оценена роль спектра светодиодного освещения в жизнедеятельности растений, и отмечено его влияние на поглощение пигментного аппарата. Рекомендовано использовать при выращивании овса в закрытом грунте полный спектр освещения в диапазоне $400-700 \mathrm{~nm}$ с доминированием красной составляющей. Выявлено, что регистрация спектров поглощения пигментов позволяет осуществлять мониторинг влияния освещения на процессы роста и развития растений. Сделано предположение, что использование источников с управляемым спектром в условиях теплицы позволит направленно воздействовать на характер биохимических реакций, протекающих в растениях при их развитии, на фотосинтез и фотоморфогенез.
\end{abstract}

DOI: $10.21883 /$ JTF.2018.09.46410.2579

\section{Введение}

Фотосинтез - процесс преобразования энергии света в энергию химических связей органических веществ. Для осуществления фотосинтеза пигменты в тканях растений должны поглощать энергию фотонов нужных длин волн и затем использовать эту энергию для запуска цепи химических реакций фотосинтеза.

Одним из первых представлений о зависимости эффективности фотосинтеза от спектрального состава было сформулировано Добени [1], который установил, что фотосинтез в отдельных диапазонах спектра идет с неодинаковой скоростью. К.А. Тимирязев предположил, что лучше всего фотосинтез протекает в красном участке спектра, хорошо поглощаемом хлорофиллом, хотя при этом Пфеффер [2] получил данные, говорящие о большей значимости ярких желтых лучей. Ломмель [3] указал на то, что, как и во всякой фотохимической реакции, решающими являются лучи, поглощаемые данной средой, - т.е. преимуществом обладают те участки спектра, которые наиболее полно поглощаются хлорофиллом. Энгельман [4] при помощи аэробных бактерий, способных передвигаться только в присутствии кислорода по выделяемому зелеными клетками кислороду при фотосинтезе, отметил наличие второго максимума фотосинтеза в сине-фиолетовом участке спектра и также связал его с наличием полосы поглощения хлорофилла.

В фотосинтезе хлорофилл играет роль оптического фотосенсибилизатора. Фотохимическую реакцию осуществляет только хлорофилл реакционного центра, остальные молекулы хлорофиллов и каротиноидов поглощают световую энергию разных длин волн и передают ее на хлорофилл реакционных центров [5]. В ре- зультате взаимодействия с белками хлорофилл меняет свои оптические свойства, что позволяет получить в составе антенных светособирающих комплексов набор его спектральных форм, спектры поглощения которых перекрывают друг друга. Тем самым обеспечивается эффективное поглощение световой энергии ансамблем антенных хлорофиллов в широком спектре с последующей ее миграцией к реакционным центрам.

Усредненная кривая фотосинтеза - зависимость интенсивности фотосинтеза от длины волны падающего света была предложена McCree [6], таким образом, он определил общий спектр действия фотосинтеза, на основе которого был вычислен усваиваемый растением поток фотонов (yield photon flux - YPF). Однако кривая YPF была построена на основе коротких измерений фотосинтеза в одном листе при низком освещении. В настоящее время определены влияния различных участков спектра освещения на физиологические процессы в растениях [7]: 280-320 nm - оказывает вредное воздействие; 320-400 nm - в малых количествах выполняет регуляторную роль; 400-500 nm - необходим для фотосинтеза и регуляции фотопериодической реакции, поглощается криптохромами и фототропинами; 500-600 nm - полезен для фотосинтеза оптически плотных листьев, листьев нижних ярусов, густых посевов растений благодаря высокой проникающей способности; 600-700 nm - ярко выраженное действие на фотосинтез, развитие и регуляцию процессов, фотоморфогенез, поглощение фитохрома $P_{660} ; 700-750 \mathrm{~nm}$ - ярко выраженное регуляторное действие при содержании в несколько процентов общей интенсивности, поглощение фитохрома $P_{730} ; 1200-1600 \mathrm{~nm}$ - поглощается внутрии межклеточной водой, увеличивает скорость тепловых 
биохимических реакций. Н.Н. Протасовой $[8]$ предложен следующий спектральный состав фотосинтетического светового потока, по ее мнению, оптимальный для сельскохозяйственных растений: $25-30 \%-$ в синей области $(380-490 \mathrm{~nm}), 20 \%$ - в зеленой $(490-590 \mathrm{~nm})$ и $50 \%$ - в красной области $(600-700 \mathrm{~nm})$.

Несмотря на наличие большого количества исследований в области светокультуры растений, до сих пор до конца не выяснен механизм влияния спектра и интенсивности фотосинтетически активной радиации на работу пигментного аппарата. Также не подобраны оптимальные условия облучения видимым светом в условиях закрытого грунта растений, с учетом их вида, сорта и вегетационного периода. К тому же, на наш взгляд, трудно создать общую концепцию тепличного освещения исходя только из оценки морфологического состояния конкретного вида растения. Содержание светочувствительных пигментов и их оптические свойства специфичны для листьев каждого вида и сорта растений и существенно изменяются в зависимости от освещения, минерального питания, возраста листьев и других внешних и внутренних условий. Различные формы пигментов имеют различающиеся максимумы поглощения, что позволяет подбирать спектральный состав света эффективный с точки зрения поглощения пигментной системой растения. Световые реакции контролируют программу развития растений и лежат в основе морфогенеза [9]. Поглощение света листом растения не совпадает полностью с поглощением пигментной системой, но последняя вносит в поглощение очень значимый вклад и определяет интенсивность фотосинтеза.

В полевых условиях, где фотосинтез и рост трудно сбалансировать [8], потенциальные возможности растения в отношении роста и продуктивности обычно реализуются лишь частично. В условиях теплицы, где используется поток видимого излучения с искусственным спектром, отличным от солнечного, теоретически возможно осуществлять с его помощью направленное воздействие на характер биохимических реакций, протекающих в растениях при их развитии, на фотосинтез и фотоморфогенез. В настоящее время широкое применение в области светокультуры растений нашли светодиодные модули, основным преимуществом которых является возможность подобрать оптимальный спектр для выращивания и адаптировать его под реальные требования вегетации растения [10].

Целью настоящей работы было изучение влияния различных светодиодных источников излучения на спектры поглощения светочувствительных пигментов растительных культур; оценка влияния интенсивности светодиодного освещения и его спектрального состава в видимой области на жизнедеятельность растительных культур в условиях закрытого грунта, выявление наиболее значимых диапазонов освещения, приводящих к более эффективному поглощению и переработке световой энергии в химическую, а также благоприятно влияющих

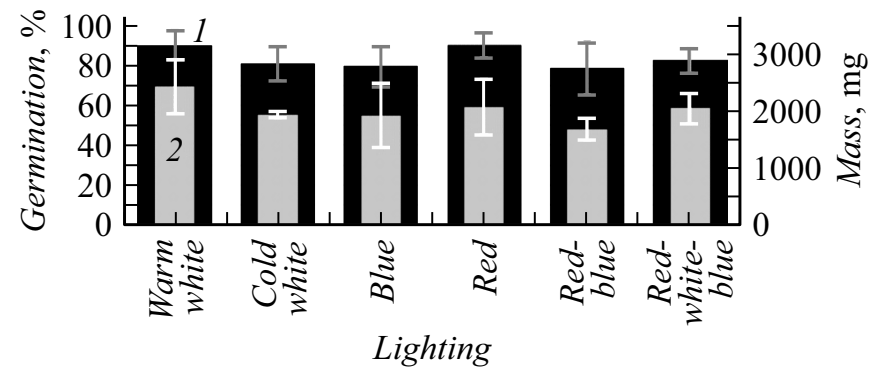

Рис. 1. Параметры всхожести (1) и массы (2) овса, выращиваемого под светом с различным спектральным составом.

на продуктивность растительных культур в условиях регулируемой окружающей среды.

\section{Исследуемые образцы и условия выращивания}

Исследование проводили в разработанном нами лабораторном фитотроне [11], обеспечивающем воспроизводимость результатов и стандартизацию условий роста и развития растений. Для изучения влияния спектра освещения на спектры поглощения и на содержание светочувствительных пигментов использовали 6 камер фитотрона, содержащих светодиодные модули, излучающие теплый белый, синий, холодный белый, красный, сине-красный и сине-бело-красный свет со значениями PPFD 190, 44, 175, 40, 71, $71 \mathrm{~mol} \cdot \mathrm{m}^{-2} \cdot \mathrm{s}^{-1}$ соответственно. Климатические условия поддерживались постоянными в течение всего исследования: температура $23 \pm 2{ }^{\circ} \mathrm{C}$, влажность воздуха $70-75 \%$.

Объектом исследования был выбран овес посевной (Avena sativa). В качестве субстрата для выращивания овса использовали гидрогель (Счастливый дачник, Россия), причем влияния цвета гидрогеля (синий, красный, желтый, фиолетовый, прозрачный) на спектр поглощения пигментов не было выявлено. После посадки отобранных семян в предварительно замоченный гидрогель образцы помещались в камеры фитотрона -3 емкости по 50 семян овса. Для оценки роли спектров облучения в жизнедеятельности растений оценивались всхожесть семян, масса 14-дневных растений, общая площадь поверхности листьев, спектр поглощения спиртовой вытяжки листьев (т.е. содержание светочувствительных пигментов) и отношение оптических плотностей на максимумах поглощения хлорофиллов $a$ и $b$.

\section{Методика регистрации спектров поглощения пигментов растений}

Экстракцию пигментов проводили по широко используемому протоколу [12]: полученная зеленая масса листьев мелко нарезалась и тщательно растиралась в 

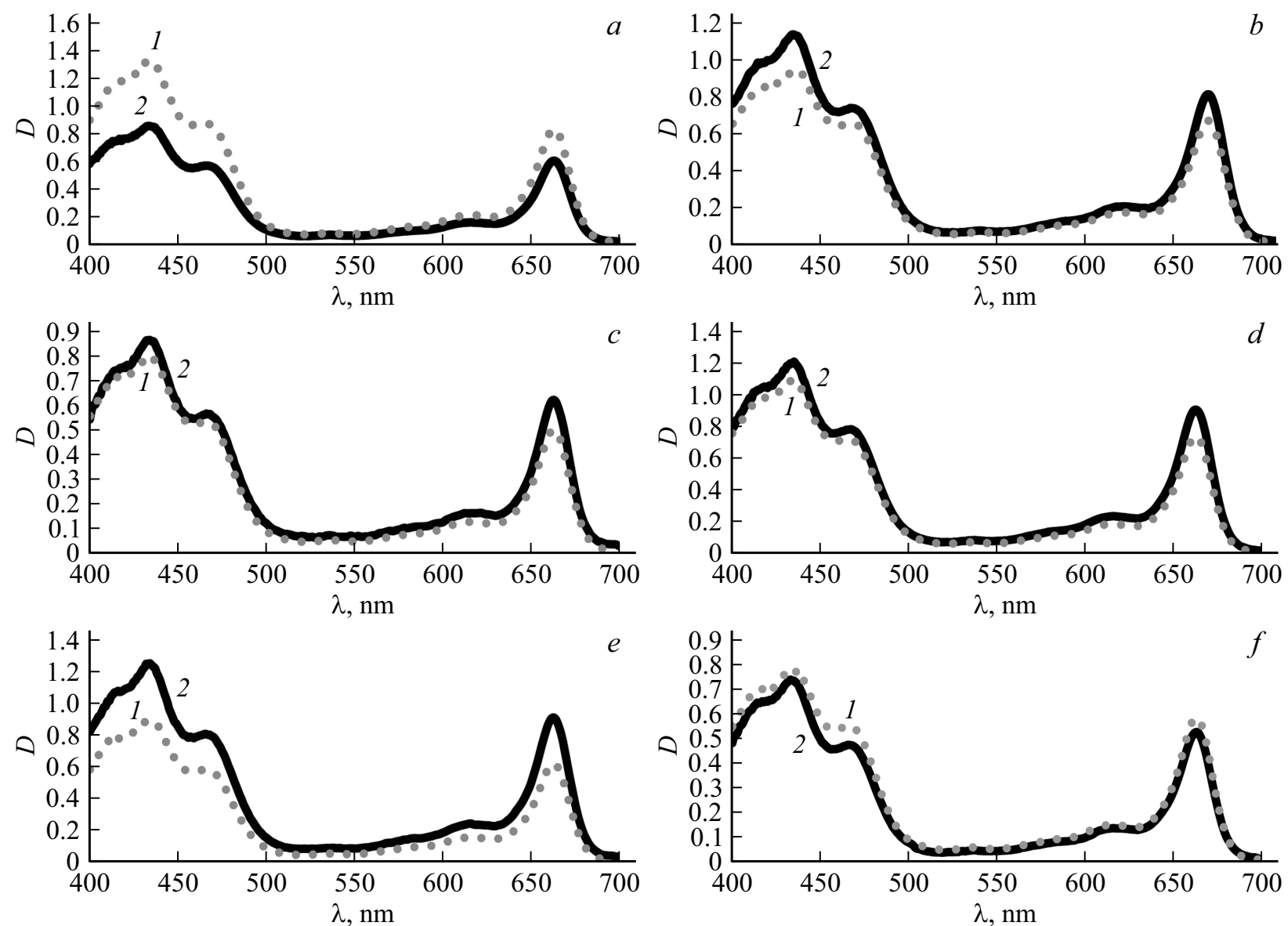

Рис. 2. Зависимость оптической плотности $D$ от длины волны для раствора пигментов, выделенных из овса посевного, освещаемого в процессе роста $a$ - теплым белым, $b-$ холодным белым, $c-$ синим, $d-$ красным, $e-$ красно-синим, $f$ - красно-бело-синим светом. Кривая 1 соответствует поглощению пигментов, выделенных из 14-дневного овса, кривая $2-$ 12-дневного.

фарфоровой ступке с 96\% этиловым спиртом (на $1 \mathrm{~g}$ листьев $10 \mathrm{ml})$ и кварцевым песком. Полученный раствор фильтровался через фильтр с размером пор 5-8 $\mu \mathrm{m}$.

Спектры поглощения спиртовых вытяжек из листьев овса измерялись в диапазоне длин волн $400-700 \mathrm{~nm}$ на спектрофотометрической установке, реализованной на базе светочувствительного монохроматора МДР-23 (Россия). В качестве источника света была использована галогенная лампа. С целью уменьшения шумов измерения выполнялись методом синхронного детектирования. Для этого между источником и входной щелью монохроматора располагался модулятор светового потока фирмы Scitec Instruments (Англия), который модулировал сигнал источника с заданной несущей частотой $333 \mathrm{~Hz}$. После выходной щели монохроматора устанавливалась кювета с образцом, проходя через которую свет попадал в детектор (ФЭУ 28). Для синхронного детектирования использовался Lock-in nanovoltmeter type 232 (Польша), который обеспечивал перемножение изменяемого сигнала и опорного с последующей фильтрацией и усилением.

Для определения доли содержания хлорофилла $a$ и хлорофилла $b$ в общей фракции пигментов исполь- зовали отношение оптических плотностей на длинах волн $433 \mathrm{~nm}\left(D_{433}\right)$ к $662 \mathrm{~nm}\left(D_{662}\right)$ - максимумы поглощения хлорофилла $a$, и $465 \mathrm{~nm}\left(D_{465}\right)$ к $616 \mathrm{~nm}$ $\left(D_{616}\right)$ - максимумы поглощения хлорофилла $b$. Также эти величины являются показателями степени поглощения в синей и красной областях спектра.

\section{Результаты}

На рис. 1 представлены морфологические показатели овса, выращенного в условиях различного по спектральному составу освещения. Всхожесть, масса и суммарная длина листьев коррелируют между собой для образцов из каждой группы, причем наблюдается тенденция к росту их значений с увеличением интенсивности излучения в красной области, как видно из данных, представленных на рис. 1. При этом, как показал эксперимент, растения лучше всего развиваются при наличии длин волн, соответствующих полному диапазону видимого света.

Как оказалось, имеется выраженная связь между спектром освещения растений и спектром поглощения 

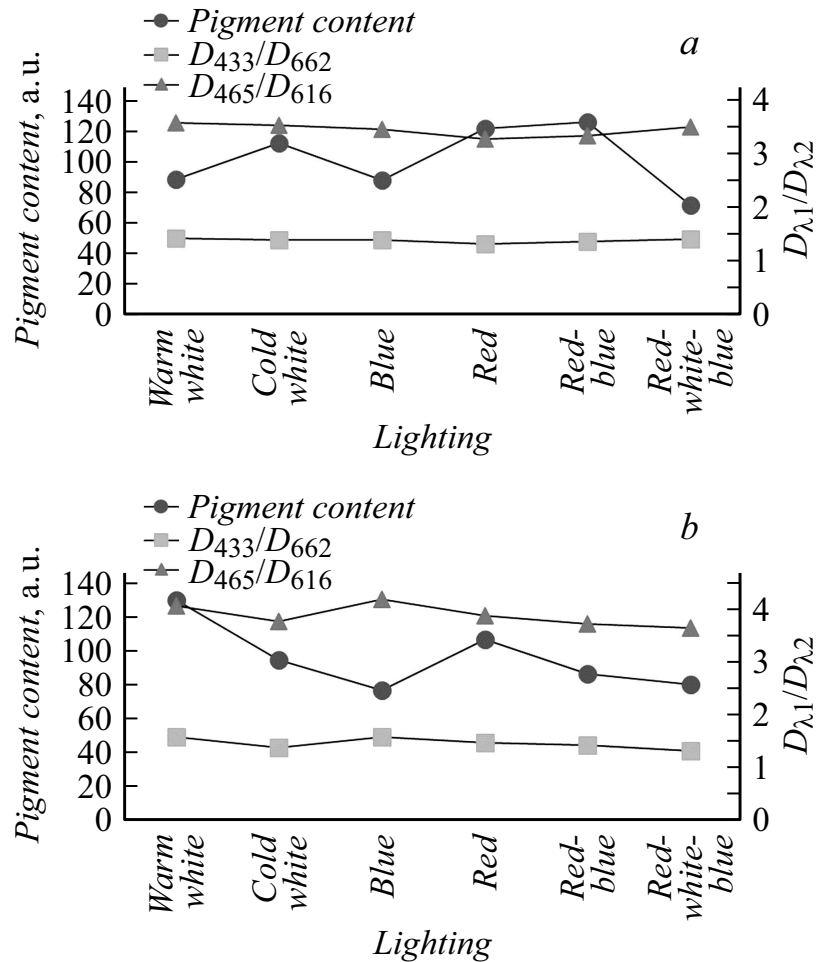

Рис. 3. Значения содержания светочувствительных пигментов и отношений оптических плотностей раствора пигментов на максимумах поглощения хлорофилла $a$ и хлорофилла $b$ для 12дневного $(a)$ и 14-дневного $(b)$ овса посевного, выращенного под светом с различным спектральным составом.

выделенных из него светочувствительных пигментов. На спектрах поглощения общей фракции светочувствительных пигментов (рис. 2), выделенных из 12-дневного и 14-дневного овса, выращенного под освещением с разными спектральными составами, видны 4 максимума поглощения. Значения оптических плотностей на длинах волн 433 и $662 \mathrm{~nm}$ характерны для максимума поглощения хлорофилла $a$, а на длинах волн 465 и $616 \mathrm{~nm}$ для хлорофилла $b$. Низкая интенсивность поглощения в зеленой области, характерной для поглощения каротиноидов, говорит об их низкой концентрации, видимо они работают только в качестве собирающих свет пигментов, а не выполняют защитные функции предохранения различных органических веществ, в первую очередь молекул хлорофилла, от разрушения на свету в процессе фотоокисления [13]. Скорее всего, это означает, что выбранные условия выращивания и освещения благоприятны для растений и у них не наблюдается стрессовых реакций, и, в частности, окислительного стресса.

По нашему мнению, содержание общей фракции светочувствительных пигментов и отношение максимумов поглощения (рис. 3), типичных для хлорофилла $a$ и $b$, являются хорошей комплексной характеристикой поглощения растениями света и работы фотосинтетического аппарата. Количество пигментов растет с увеличением возраста растений, освещаемых теплым белым и красно- бело-синим светом, и падает для образцов, выращенных под светом с большей долей синего света. Для 12дневного овса разброс в значениях отношений оптических плотностей не велик $(6-7 \%)$, но увеличивается

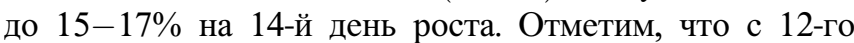
по 14-ый день длина листьев растений увеличивалась в среднем на $50 \%$, а в условиях выращивания в гидрогеле 15-ый день может рассматриваться как конец вегетационного периода. Соответственно 12-ый день это период максимальной скорости роста растения, а 14-ый - начало увядания первых листьев. Большие изменения в поглощение в зависимости от условий освещения наблюдаются для хлорофилла $b$, так как по литературным данным известно [14], что этот пигмент реагирует на недостаток света в какой-либо области.

Изменение отношений максимумов поглощения показывает, что при избытке излучения в каком-либо диапазоне длин волн пигментный аппарат растения поглощает большее количество фотонов с энергией, характерной для доминирующей области излучения, что хорошо вписывается в представления о способности к адаптации пигментной системы растительных культур, ответственной за фотосинтез. Например, при освещении синим светом растение более приспособлено к переработке квантов, характерных для этого диапазона; соответственно и пигментный аппарат поглощает больше синей составляющей спектра по сравнению с красной. Однако имеется и противоположный процесс: при отсутствии длинноволновой части спектра освещения фотосинтетические пигменты пытаются их уловить, повышая тем самым чувствительность к красному свету. Это соответствует принятому в литературе представлению о том, что фотосинтетическая эффективность поглощения квантов в области $650-680 \mathrm{~nm}$ выше, чем для области $400-460 \mathrm{~nm}$, и значительной роли длин волн 680 и $700 \mathrm{~nm}$, как максимумов поглощения пигментов $P_{700}$ фотосистемы I и $P_{680}$ фотосистемы II - реакционных центров, используемых для первичной фотохимической реакции переноса электронов [15]. В ходе исследования было также показано, что вариация интенсивности красной составляющей в освещении изменяет относительное поглощение пигментов, что соответствует представлениям о значительной роли красного диапазона в процессах фотоморфогенеза.

\section{Заключение}

При сравнении содержания хлорофилла $a$, хлорофилла $b$ и общего содержания пигментов со всхожестью, динамикой роста, массой и площадью поверхности листьев овса посевного выявлено, что более эффективным является использование спектра освещения с излучением во всей области длин волн от 400 до $700 \mathrm{~nm}$ и с доминированием красной составляющей. Оптимальная интенсивность освещения, полученная в ходе проведенных экспериментов, составляет $70-100 \mu \mathrm{mol} \cdot \mathrm{m}^{-2} \cdot \mathrm{s}^{-1}$ 
для овса посевного при облучении в сине-бело-красном диапазоне.

Применяя энергоэффективные светодиодные технологии, важно понимать какие интенсивности и спектры освещения требуются растениям для нормальной жизнедеятельности. Получение спектров поглощения фотосинтетических пигментов конкретных культур позволяет предложить принцип подбора спектра излучения светодиодных модулей для основного освещения этих культур в тепличных комплексах. Спектры поглощения светочувствительных пигментов могут являться показателем светодефицита или наоборот перенасыщения во всем диапазоне видимого спектра. Разработанная методика регистрации спектров поглощения пигментов позволяет быстро снимать спектры и эффективно оценивать их изменения в зависимости от измеряемого образца и условий его выращивания. Конечным продуктом может стать энергоэффективный источник света со спектром излучения, подобранным с учетом реальных данных о состоянии и физиологических показателях выращиваемых растений.

Таким образом, полученные результаты могут быть использованы в сельском хозяйстве для ускорения роста и развития растений, для повышения урожайности и качества продуктов растениеводства, за счет создания спектра освещения, наиболее благоприятно влияющего на продуктивность, а также в фитотронных системах в качестве показателя фотосинтетической активности листьев растительных культур.

Спектрофотометрические исследования выполнены с использованием оборудования федерального ЦКП „Материаловедение и диагностика в передовых технологиях“, поддержанного Минобрнауки России (уникальный идентификатор проекта RFMEFI62117X0018).

\section{Список литературы}

[1] Daubeny C. // Philosophical Transactions of the Royal Society of London. 1836. Vol. 126. P. 149-175.

[2] Pfeffer $W$. // Annalen der Physik. 1873. Vol. 224. N 1. P. 86-99.

[3] Lommel E. // Annalen der Physik. 1871. Vol. 219. N 8. P. 568-585.

[4] Engelmann T.W. // Archiv für die gesamte Physiologie des Menschen und der Tiere. 1882. Vol. 29. N 1. P. 387-400.

[5] Медведев С.С. Физиология растений. СПб.: БХВ-Петербург, 2012. 512 с.

[6] McCree K.J. // Agricultural Meteorology. 1971. Vol. 9. P. 191-216.

[7] Тихомиров А.А., Шарупич В.П., Лисовский Г.М. Светокультура растений: биофизические и биотехнологические основы. Новосибирск: Изд-во СО РАН, 2000. 213 с.

[8] Протасова Н.Н. // Физиология растений. 1987. Т. 34. № 4. C. $812-822$.

[9] Воскресенская Н.П. Фотосинтез и спектральный состав света. М.: Наука, 1965. 309 с.

[10] Randall W.C., Lopez R.G. // Hort Science. 2014. Vol. 49. N 5. P. 589-595.
[11] Кулешова Т.Э., Блашенков М.Н., Кулешов Д.О., Галль Н.Р. // Научное приборостроение. 2016. Т. 26. № 3. C. $35-43$.

[12] Lichtenthaler H.K. // Methods in Enzymology. 1987. Vol. 148. P. 350-382.

[13] Тихонов A H. // Соросовский образовательный журнал. 1999. № 11. C. 16-21.

[14] Boardman N.K. // Annual Review of Plant Physiology. 1977. Vol. 28. N 1. P. 355-377.

[15] Холл Д., Рао К. Фотосинтез. М.: Мир, 1983. 134 с. 